\title{
Synthesis of Covalently Linked Porphyrin Heterodimers with Potential Use in Solar Energy Conversion Devices
}

\author{
Nadejda V. Konovalova, ${ }^{@}$ Elena V. Kirienko, and Valentina N. Luzgina \\ M.V. Lomonosov Moscow State University of Fine Chemical Technologies, 119571 Moscow, Russian Federation \\ ${ }^{\circledR}$ Corresponding author E-mail: nadejda_73@mail.ru
}

\begin{abstract}
The synthesis and spectral properties of porphyrin derivative dyads are described. The dyads consist of free base 2-(2-carboxyvinyl)-5,10,15,20-tetraphenylporphyrin covalently linked to zinc 5-(p-aminophenyl)-10,15,20triphenylporphyrin by an amide bond. These dyads differ from each other by mutual orientation of two porphyrin moieties resulting from different configuration of double bond in a spacer group. The dyads were obtained by the coupling reaction between the acid chloride derivatives of either Z-or E-isomer of acid porphyrin and the amino porphyrin and characterized with a set of spectral methods.
\end{abstract}

Keywords: Porphyrins, heterodimers, synthesis, energy conversion.

\section{Introduction}

meso-Substituted porphyrins are main structural components used in a large number of model systems in biomimetic and material chemistry. ${ }^{[1-9]}$ Porphyrin-based assemblies have important applications in the development of artificial devices for solar energy conversion into chemical potential or electrical energy in common with that effected by natural photosynthetic systems. ${ }^{[7,10-14]}$ Studies performed with many donor-acceptor model systems ${ }^{[1-5,15-}$ ${ }^{20]}$ revealed the effects of structural factors, such as distance and orientation, as well as electronic nature of the spacer, driving force, temperature and solvent on the rates and quantum yields of the energy transfer and charge separation processes. Porphyrin dimers are good photosynthetic models in which the geometry, distance and angle between the porphyrin moieties strongly influence on the efficiency of the photophysical processes. A large number of covalently and non-covalently linked porphyrin-based dimers with various constraints (e.g. nature of spacers, distance and orientation of donor with respect to acceptor) have been synthesized and their photophysical properties have been described in literature. ${ }^{[3,21-35]}$ Irradiation of a donor pigment within a porphyrin dimer is followed by an effective energy transfer and, in some cases, a direct transformation of sunlight energy to the charge-separated state by means of electron transfer.

An important demand to design of the effective energy and electron transferring diporphyrin systems consists in assembling of two different macrocycles with nonidentical spectral characteristics. That allows a selective excitation of one porphyrin moiety of dyad and provides a driving force for energy or electron transfer after irradiation. Examples of directional energy transfer between two different macrocycles include: a tetraarylporphyrin covalently linked to a pyropheophorbide, ${ }^{[22]}$ a porphyrin-sapphyrin heterodimer which is held together by hydrogen bonds, ${ }^{[23]}$ covalently linked chlorophyll-porphyrin ${ }^{[24]}$ and zinc porphyrin-pheophorbide ${ }^{[25]}$ heterodimers, porphyrin-chlorin dyads with aryl spacer ${ }^{[26]}$ and ether linkage between macrocycles, ${ }^{[27]}$ porphyrin-phthalocyanine dyads, ${ }^{[28,29]}$ several heteroporphyrin dyads with amide linkage ${ }^{[30,31]}$ and phenylene bridging group, ${ }^{[32]}$ diporphyrins containing a normal porphyrin and a thiaporphyrin cores, ${ }^{[33]}$ phenylethyne-linked dyads in which the ethyne-substituted porphyrin serves as the acceptor while the phenyl-substituted porphyrin serves as the donor ${ }^{[34]}$ and recently described "clicked" dimers of unsymmetrically substituted tetraphenylporphyrins. ${ }^{[35]}$ Unsymmetrical porphyrin dimers are not only useful models for mimicry of photosynthetic energy and electron transfer but its have a potential application in the spectral sensitization of semiconductor solar cells. ${ }^{[1,35]}$ Therefore, the synthesis and investigation of well-defined asymmetric dyads based on porphyrin derivatives is of interest for the development of new photoactive energy converting architectures.

In the present work we report the synthesis of porphyrin dyads, in which the free base porphyrin moiety - 2-(2carboxyvinyl)-5,10,15,20-tetraphenylporphyrin - is attached to zinc 5-( $p$-aminophenyl)-10,15,20-triphenylporphyrin by an amide bond. Introduction of a double bond directly to a $\beta$-position of the porphyrin macrocycle results in a modulation of the spectral characteristics, particularly, a red shift by $\sim 10 \mathrm{~nm}$ in the electronic absorption spectrum. The two macrocycles possess thus different electronic properties of their $\pi$-systems which allows selectively irradiate one of them with a suitable wavelength and observe directed energy transfer after photoexcitation. Because of the zinc porphyrin moiety of dyads absorbs at wavelengths (550 and $593 \mathrm{~nm}$ ) where free base porphyrin moieties have minimum of absorption, combined systems of these porphyrins should cover a large part of the visible region of the solar spectrum, thereby revealing an increased light harvesting capacity with retaining at the same time the individual electronic features of the component porphyrins. By changing the double bond configuration in the rigid linkage group, the different mutual 
arrangement of two chromophores in the dyads may be achieved. Preliminary studies of photophysical properties of synthesized porphyrin dyads were performed and the results demonstrated that the efficient singlet energy transfer actually occurs from the electronically excited state of the zinc porphyrin to the free base porphyrin in both dyads. ${ }^{[36]}$

\section{Experimental}

Reagents used in this study were obtained from Fluka Chemical Co. Pyrrole was distilled under reduced pressure immediately prior to use. Dry dimethylformamide was prepared by azeotropic distillation with benzene $(10 \% \mathrm{v} / \mathrm{v}$, previously dried over $\mathrm{CaH}_{2}$ ) under reduced pressure. Pure thionyl chloride was obtained by distillation from boiled linseed oil $(2 \%)$. All other reagents were used without further purification. All solvents were dried and distilled prior to use according to the standard methods. Reactions were monitored on Silufol UV-254 TLC plates (Kavalier, Czechia). The silica gel $60(0.040-0.063 \mathrm{~mm})$ from Merck was utilized for column chromatography. Porphyrins $1-4^{[37]}$ and porphyrins 5-9 ${ }^{[38]}$ were synthesized according to the procedures described in the respective literature.

${ }^{1} \mathrm{H}$ NMR spectra were recorded on Bruker DPX $300 \mathrm{MHz}$ spectrometer in $\mathrm{CDCl}_{3}$; chemical shifts $\delta_{\mathrm{H}}$ are expressed in parts per million relative to TMS as an internal standard. IR spectra were recorded on Shimadzu IR-435 spectrometer. MALDI-TOF mass spectra were obtained on Vision 2000 spectrometer with 2,4,6-trihydroxyacetophenone as the matrix. UV-vis spectra were measured using either JASCO UV-7800 or Perkin Elmer Lambda 35 spectrophotometer.

E-isomer of $\{5-[4-(5,10,15,20$-tetraphenylporphyrin-2-yl) acryloylaminophenyl]-10,15,20-triphenylporphyrinato ;zinc(II) (E-10). E-isomer of porphyrin 9 (14 $\mathrm{mg}, 0.020 \mathrm{mmol})$ was dissolved in dry benzene $(2 \mathrm{ml})$ under argon and thionyl chloride $(70 \mu 1,0.98$ mmol) was added. The reaction mixture was stirred for $30 \mathrm{~min}$ at rt. The solvent and excess of thionyl chloride were removed under reduced pressure. A solution of amino porphyrin 4 (11.8 $\mathrm{mg}, 0.017$ mmol) and DMAP $(2.5 \mathrm{mg}, 0.020 \mathrm{mmol})$ in benzene $(3 \mathrm{ml})$ was added to the dry residue of the acid chloride. After stirring at $\mathrm{rt}$ under argon atmosphere in the dark for $36 \mathrm{~h}$, the reaction mixture was washed with aqueous $\mathrm{HCl}(36 \mathrm{ml}, 1 \mathrm{~N})$ and water, extracted with benzene and dried over anhydrous $\mathrm{Na}_{2} \mathrm{SO}_{4}$. The solvent was evaporated under reduced pressure. The crude product was purified by silica gel column chromatography (eluent dichloromethane/ hexane 2:1) to afford $E$-10 (18 mg, 78\%). $R_{\mathrm{f}}\left(\mathrm{CHCl}_{3} /\right.$ hexane $\left.4: 1\right)$ $=0.25 . \mathrm{m} / \mathrm{z}$ (MALDI-TOF): 1356.9 (calcd. for $\left[\mathrm{M}^{+}\right]$1357.4). IR $(\mathrm{KBr}) v_{\max } \mathrm{cm}^{-1}: 3417$ (N-H st), 2917 (C-H st), 1648 (C=O st), 1583 $(\mathrm{C}=\mathrm{C} \mathrm{st}), 1523(\mathrm{~N}-\mathrm{H} \delta), 1017(\mathrm{C}-\mathrm{H} \delta)$. UV-vis (benzene) $\lambda_{\max } \mathrm{nm}$ (rel. intensity): 425 (0.863), 524 (0.036), 554 (0.043), 597 (0.021), 657 (0.006). ${ }^{1} \mathrm{H}$ NMR $\left(\mathrm{CDCl}_{3}\right) \delta_{\mathrm{H}} \mathrm{ppm}: 9.01(1 \mathrm{H}, \mathrm{d}, J=0.80 \mathrm{~Hz}$, $3-\beta-\mathrm{H}$ in $\mathrm{H}_{2}$ TPP), 8.97 ( $2 \mathrm{H}, \mathrm{d}, J=4.71 \mathrm{~Hz}, \beta-\mathrm{H}$ in $\left.\mathrm{ZnTPP}\right), 8.91$ $(2 \mathrm{H}, \mathrm{d}, J=4.71 \mathrm{~Hz}, \beta-\mathrm{H}$ in ZnTPP), 8.85 (4H, br s, $\beta-\mathrm{H}$ in ZnTPP), 8.80-8.74 (6H, m, $\beta$-H in $\mathrm{H}_{2}$ TPP), 8.25-8.13 (16H, m, Ph), 8.02$7.87(5 \mathrm{H}, \mathrm{m}, \mathrm{Ph}), 7.80-7.64(18 \mathrm{H}, \mathrm{m}, \mathrm{Ph}), 7.26(1 \mathrm{H}, \mathrm{dd}, J=0.80$, $15.7 \mathrm{~Hz},-\mathrm{CH}=\mathrm{CHCO}-), 6.79$ (1H, d, $J=15.7 \mathrm{~Hz},-\mathrm{CH}=\mathrm{CHCO}-)$, $6.20(1 \mathrm{H}$, br s, -NHCO- $),-2.56(2 \mathrm{H}, \mathrm{s}$, pyrrole $\mathrm{NH})$.

Z-isomer of $\{5-[4-(5,10,15,20$-tetraphenylporphyrin-2-yl) acryloylaminophenyl]-10,15,20-triphenylporphyrinato zzinc(II) (Z-10). Z-Isomer of porphyrin $9(12 \mathrm{mg}, 0.018 \mathrm{mmol})$ was dissolved in dry benzene $(2 \mathrm{ml})$ under argon and thionyl chloride ( $70 \mu 1,0.98$ $\mathrm{mmol}$ ) was added. The reaction mixture was stirred for $30 \mathrm{~min}$ at rt. The solvent and excess of thionyl chloride were removed under reduced pressure. A solution of amino porphyrin 4 (10.4 mg, 0.015 mmol) and DMAP $(2.2 \mathrm{mg}, 0.018 \mathrm{mmol})$ in benzene $(3 \mathrm{ml})$ was added to the dry residue of the acid chloride. After stirring at $\mathrm{rt}$ under argon in the dark for $36 \mathrm{~h}$, the reaction mixture was washed with aqueous $\mathrm{HCl}(36 \mathrm{ml}, 1 \mathrm{~N})$ and water, extracted with benzene and dried over anhydrous $\mathrm{Na}_{2} \mathrm{SO}_{4}$. The solvent was evaporated under reduced pressure. The crude product was purified by silica gel column chromatography (eluent dichloromethane/hexane 2:1) to afford Z-10 $(15 \mathrm{mg}, 73 \%) . R_{\mathrm{f}}\left(\mathrm{CHCl}_{3} /\right.$ hexane $\left.4: 1\right)=0.3 . \mathrm{m} / \mathrm{z}$ (MALDI-TOF): 1357.0 (calcd. for $\left[\mathrm{M}^{+}\right]$1357.4). IR (KBr) $v_{\max } \mathrm{cm}^{-1}$ : 3408 (N-H st), 2917 (C-H st), 1651 (C=O st), 1594 (C=C st), 1520 $(\mathrm{N}-\mathrm{H} \delta), 1019(\mathrm{C}-\mathrm{H} \delta)$. UV-vis (benzene) $\lambda_{\max } \mathrm{nm}$ (rel. intensity): 423 (0.592), 519 (0.036), 551 (0.046), 594 (0.015), 652 (0.006). ${ }^{1} \mathrm{H}$ NMR $\left(\mathrm{CDCl}_{3}\right) \delta_{\mathrm{H}}$ ppm: $8.94\left(1 \mathrm{H}, \mathrm{s}, 3-\beta-\mathrm{H}\right.$ in $\left.\mathrm{H}_{2} \mathrm{TPP}\right), 8.90-8.79$ (8H, $\mathrm{m}, \beta-\mathrm{H}$ in $\mathrm{ZnTPP}), 8.76-8.71\left(6 \mathrm{H}, \mathrm{m}, \beta-\mathrm{H}\right.$ in $\left.\mathrm{H}_{2} \mathrm{TPP}\right), 8.23-$ $7.75(39 \mathrm{H}, \mathrm{m}, \mathrm{Ph}), 7.22(1 \mathrm{H}, \mathrm{d}, J=12.0 \mathrm{~Hz},-\mathrm{CH}=\mathrm{CHCO}-), 6.93$ $(1 \mathrm{H}, \mathrm{d}, J=12.0 \mathrm{~Hz},-\mathrm{CH}=\mathrm{CHCO}-), 5.65(1 \mathrm{H}, \mathrm{br} \mathrm{s},-\mathrm{NHCO}-),-2.47$ (2H, s, pyrrole $\mathrm{NH})$.

\section{Results and Discussion}

\section{Synthesis of Porphyrins}

The molecular structures of proposed dyads require the synthesis of asymmetric porphyrins, such as meso-substituted porphyrin bearing the functional amino group in one of the meso-phenyl rings ( $\mathrm{AB}_{3}$ porphyrin) and meso-substituted porphyrin with the functional carboxyl group at $\beta$-position of a macrocycle to make the link between porphyrin moieties. Porphyrin bearing two different types of meso-substituents can be prepared by a binary mixed aldehyde condensation. ${ }^{[39,40]}$ Although this approach is statistical in nature and multiple porphyrin products are usually obtained, the isolation of required porphyrin by chromatographic separation is generally possible. At the same time a symmetric porphyrin bearing four identical meso-substituents that is always formed in this condensation may be used to functionalize its $\beta$-position, particularly by the Vilsmeier formylation and further modification of a formyl group.

The condensation of pyrrole with benzaldehyde and 4-nitrobenzaldehyde (4:3:1 molar ratio) catalyzed by monochloroacetic acid in boiling $o$-xylene with subsequent oxidation of reaction mixture with 2,3-dichloro-5,6-dicyano1,4-benzoquinone (DDQ) affords the mixture of porphyrin products with predominance of 5-( $p$-nitrophenyl)-10,15,20triphenylporphyrin (1) and 5,10,15,20-tetraphenylporphyrin (2) (Scheme 1). ${ }^{[37]}$

Flash chromatography on alumina using $o$-xylene as eluent allowed to separate these two porphyrins from the other minor porphyrin products and polypyrromethene oligomers. Then the mixture of porphyrins $\mathbf{1}$ and $\mathbf{2}$ without further separation underwent reduction with $\mathrm{SnCl}_{2}$ in concentrated hydrochloric acid to give 5-( $p$-aminophenyl)-10,15,20triphenylporphyrin (3) and remaining tetraphenylporphyrin (2). These two porphyrins were easily separated by flash chromatography on silica gel with high level of purity using benzene-chloroform. The first purple band corresponded to meso-tetraphenylporphyrin $2\left(R_{\mathrm{f}} 0.7\right)$ and the second was the mono-aminoporphyrin $\mathbf{3}\left(R_{\mathrm{f}} 0.2\right)$. Thus, the desired porphyrins 2 and 3 were obtained in 9 and $4 \%$ yields, respectively. Aminoporphyrin 3 was treated with zinc acetate to afford $\mathrm{Zn}$ aminoporphyrin 4 (96\% yield) which was used as an amino component in the synthesis of porphyrin dyads.

The 5,10,15,20-tetraphenylporphyrin (2) was used as a starting material in the preparation of 2-(2-carboxyvinyl)5,10,15,20-tetraphenylporphyrin (9) - an acid component of porphyrin dyads (Scheme 2). The porphyrin 2 was 


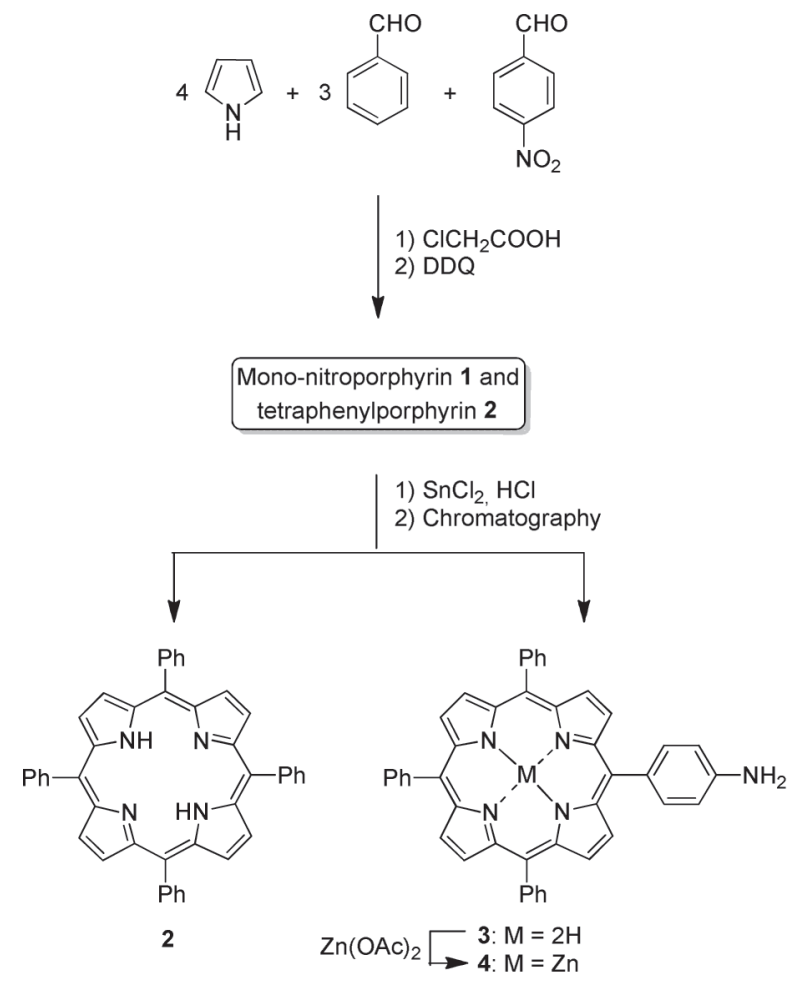

Scheme 1. Synthesis of porphyrins 2 and 4 .

converted into a $\mathrm{Cu}$ complex $\mathbf{5}$ and then the introduction of formyl group into the porphyrin macrocycle by Vilsmeier reaction was performed for a further functionalization of the macrocycle. ${ }^{[38]}$ Thus, formylation of $\mathrm{Cu}$ porphyrin $\mathbf{5}$ with $\mathrm{POCl}_{3}$-DMF in refluxing 1,2 -dichloroethane gave ( $\beta$-formylmeso-tetraphenylporphyrinato)copper(II) (6) as the main product which was isolated in $88 \%$ yield after column chromatography.

The presence of the reactive formyl group at the $\beta$-position of porphyrin macrocycle allowed to perform the Wittig reaction with (methoxycarbonylmethylene)triphenylphosphorane using a standard procedure. ${ }^{[38]}$ This condensation afforded two porphyrins which were separated by column chromatography on silica gel using benzene as eluent. The mass spectrum (MALDI-TOF) of porphyrin products mixture exhibited the only signal of parent ion at $\mathrm{m} / \mathrm{z}$ 760.22 that allowed us attributing them to the two isomers of acrylic acid ester 7 . Thus, $Z$ - and $E$-isomers of porphyrin 7 were prepared in 29 and $45 \%$ yields, respectively.

Each of isomers $Z-7$ and $E-7$ was treated with $\mathrm{POCl}_{3}$ mixed with water to afford metal-free porphyrins $Z-8$ and $E-8$ in 91 and $93 \%$ yields, respectively. The hydrolysis of these ester porphyrins by heating with $2 \mathrm{~N} \mathrm{KOH}$ in water-pyridine medium gave corresponding acids $-Z$ - and $E$-isomers of 2-(2-carboxyvinyl)-5,10,15,20-tetraphenylporphyrin 9. The double bond configuration in prepared isomers of porphyrin 9 was confirmed by NMR spectroscopy. The protons of alkenyl substituent were represented by a pair of doublets with spinspin coupling constants equal to $15 \mathrm{~Hz}$ for $E$-isomer and $12 \mathrm{~Hz}$ for $Z$-isomer of porphyrin 9 that corresponds to the published data. ${ }^{[38,41]}$

Once in hand, the key functionally substituted porphyrin derivatives 4, E-9 and Z-9 were used to prepare covalently
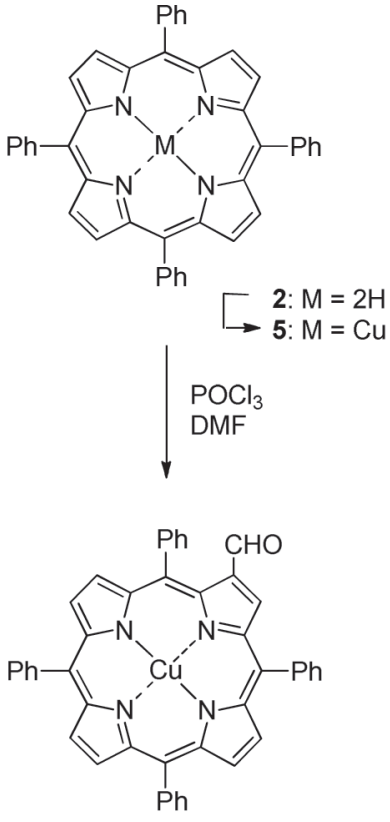

6

1) $\mathrm{Ph}_{3} \mathrm{P}=\mathrm{CH}-\mathrm{CO}_{2} \mathrm{Me}$ 2) Chromatography
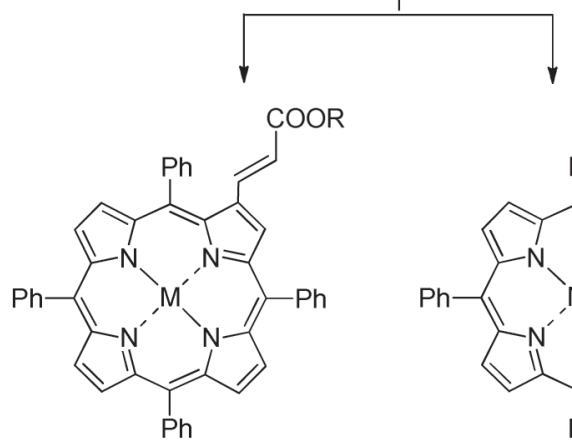

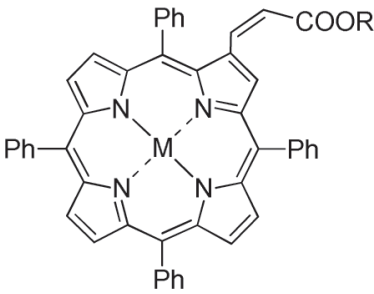

E-7: $M=\mathrm{Cu}, \mathrm{R}=\mathrm{Me}$
$\longrightarrow E-8: M=2 \mathrm{H}, \mathrm{R}=\mathrm{Me}$
$\longrightarrow E-9: M=2 \mathrm{H}, \mathrm{R}=\mathrm{H}$

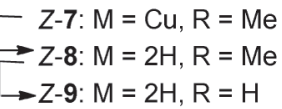

Scheme 2. Synthesis of $Z$ - and $E$-isomers of the 2-(2-carboxyvinyl)-5,10,15,20-tetraphenylporphyrin.

linked porphyrin dyads with different configuration of double bond in a spacer group.

\section{Synthesis and Characterization of Dyads}

To synthesize the desired porphyrin dyads (Scheme 3), the carboxylic groups of the acid porphyrins E-9 and Z-9 were transformed into an acid chloride using thionyl chloride in dry benzene. ${ }^{[31,42]}$

The acid chlorides were not isolated but immediately after removing of thionyl chloride excess were used for coupling with $\mathrm{Zn}$ aminoporphyrin 4 in the presence of a catalytic amount of 4-(dimethylamino)pyridine (DMAP). The desired porphyrin dyads $E-\mathbf{1 0}$ and $Z-\mathbf{1 0}$ were isolated by means of silica gel column chromatography in 78 and $73 \%$ yields, respectively, and characterized by their electronic absorption, IR, ${ }^{1} \mathrm{H}$ NMR and mass spectra.

The obvious indicator of the 2-carboxyvinyl-5,10,15,20tetraphenylporphyrin fragment in ${ }^{1} \mathrm{H}$ NMR spectra of $E$-10 


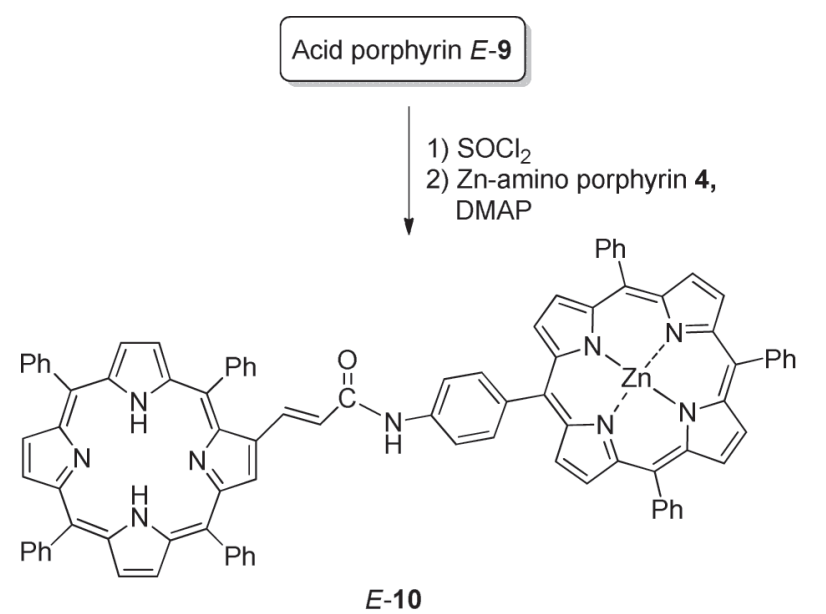

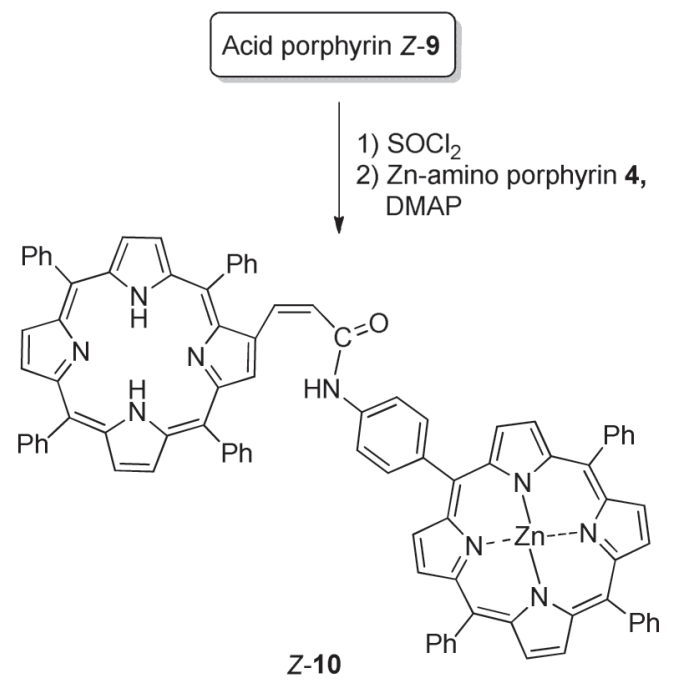

and $Z-\mathbf{1 0}$ is the presence of the unique 3- $\beta$-proton signal and the multiplet for the six inequivalent porphyrin $\beta$-protons on the other three pyrrole rings (Figure 1). For the $\mathrm{Zn}$ aminoporphyrin fragment, two $\mathrm{AB}$ doublets were observed for the two pairs of equivalent $\beta$-protons on the pyrrole rings neighbouring on the para-substituted phenylene unit, while four $\beta$-protons on the other two equivalent rings give an unresolved singlet. The two doublets for the ethenyl protons of the spacer group $(J=15.7$ and $12.0 \mathrm{~Hz}$ for $E$ - and $Z-10$, respectively) were observed in both cases. There is a clear distinction between the chemical shifts of two alkene $\mathrm{CH}$ units of the spacer groups. The $\beta$-attached $\mathrm{CH}$ protons appear at 7.26 and $7.22 \mathrm{ppm}$ for $E \mathbf{- 1 0}$ and $Z \mathbf{- 1 0}$, respectively. Conversely, those next to the CONH group resonate at 6.79 and $6.93 \mathrm{ppm}$ for $E \mathbf{- 1 0}$ and $Z \mathbf{- 1 0}$, respectively. This order of shifts is congruent with those for the $\mathrm{CH}$ protons in the $\beta$-acryl derivatives $E$-8 and $Z-8$ (7.41 and 6.90 ppm for the $\beta$-attached $\mathrm{CH}$ protons, 6.55 and $5.65 \mathrm{ppm}$ for those linked to the carbonyl group, respectively) ${ }^{[38]}$ and is due to a ring current effect of the neighbouring tetrapyrrole ring.

The binuclear structures of dyads $E-\mathbf{1 0}$ and Z-10 were apparent from their mass spectra. Accurate mass measurements were received using MALDI-TOF, which exhibited a clear $\left[\mathrm{M}^{+}\right]$ions at the expected $\mathrm{m} / \mathrm{z}$ values.

\section{Absorption Spectra}

The absorption spectra of porphyrin monomers and dyads in benzene are shown in Figure 2. The spectrum of the $\mathrm{Zn}$ aminoporphyrin 4 exhibits a Soret band at $422 \mathrm{~nm}$ and $Q$-bands with maxima at 550 and $593 \mathrm{~nm}$. The free base acid porphyrin $E \mathbf{- 9}$ has maximum at $430 \mathrm{~nm}$ (Soret band) and four $Q$-bands at 523, 561, 602 and $657 \mathrm{~nm}$. The spectrum of dyad $E$-10 (Figure 2a) has the one large absorption band in the Soret region at $425 \mathrm{~nm}$, which is situated between the Soret bands of $\mathrm{Zn}$ porphyrin 4 and free base porphyrin $E-9$, and $Q$-bands at 524, 554, 597

Scheme 3. Synthesis of porphyrin dyads $E-\mathbf{1 0}$ and $Z-\mathbf{1 0}$.

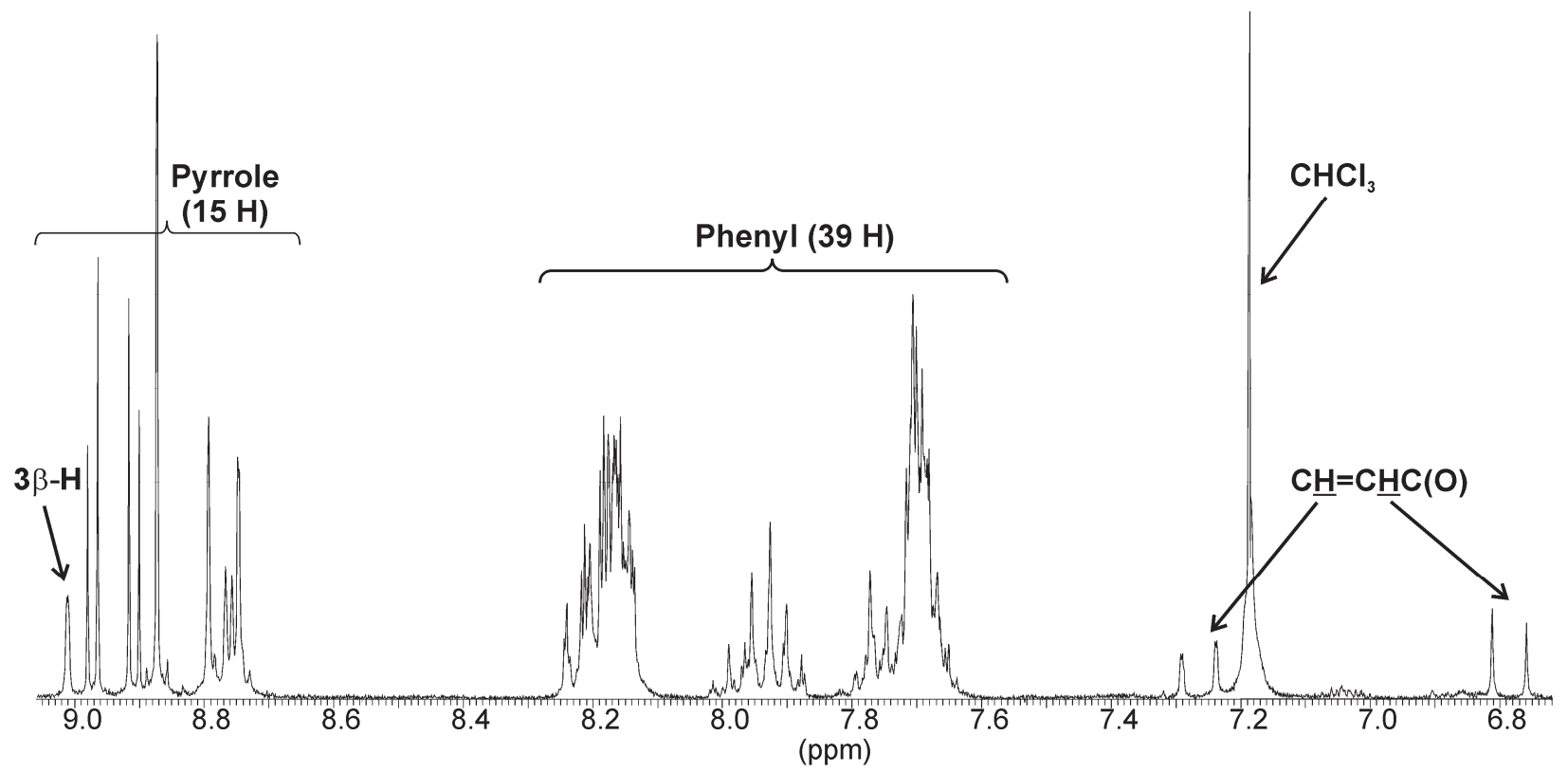

Figure 1. Downfield region of the ${ }^{1} \mathrm{H}$ NMR spectrum of dyad $E-10$ in $\mathrm{CDCl}_{3}$. 

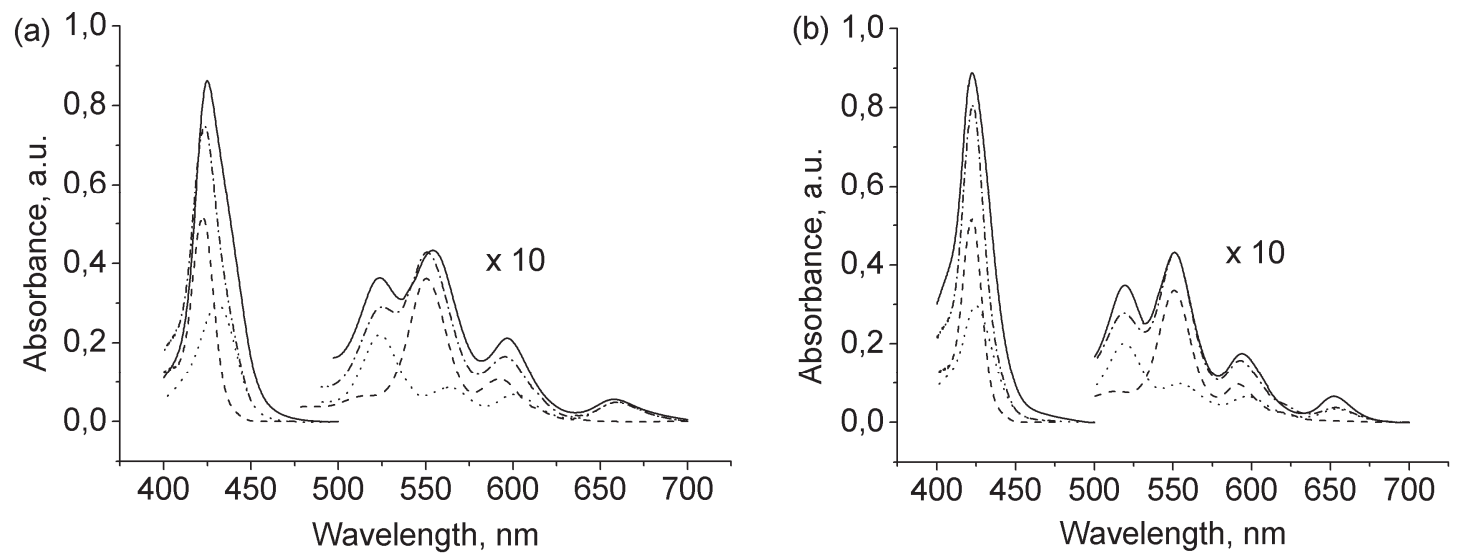

Figure 2. UV-visible absorption spectra of: (a) Zn aminoporphyrin 4 (dashed line), free base porphyrin $E-\mathbf{9}$ (dotted line), dyad $E$-10 (solid line) and a linear combination of the spectra of porphyrins 4 and $E-9$ (dash dotted line); (b) Zn aminoporphyrin 4 (dashed line), free base porphyrin Z-9 (dotted line), dyad Z-10 (solid line) and a linear combination of the spectra of porphyrins 4 and Z-9 (dash dotted line) in benzene.

and $657 \mathrm{~nm}$. The absorption spectrum of dyad $E-\mathbf{1 0}$ in the visible region is thus essentially a linear combination of the spectral features of the constituent monomers with only minor differences in band wavelengths and intensities (Figure 2a). The absorption bands of dyad $E \mathbf{- 1 0}$ at 523 and $656 \mathrm{~nm}$ are similar to the absorption bands of porphyrin $E-9$ at 524 and $657 \mathrm{~nm}$ and can thus be assigned to the free base moiety of the dyad. At the same time, the absorption bands of the dyad $E-\mathbf{1 0}$ at 554 and $597 \mathrm{~nm}$ correspond to an additive contribution of the spectral features of the $\mathrm{Zn}$ porphyrin 4 at 550 and $593 \mathrm{~nm}$ and the free base porphyrin $E-9$ at 561 and $602 \mathrm{~nm}$.

The spectral features of dyad $Z-10$, the $\mathrm{Zn}$ aminoporphyrin 4 and the free base acid porphyrin $Z-9$ are compared in Figure $2 \mathrm{~b}$. The Soret band of dyad Z-10 has a maximum at $422 \mathrm{~nm}$ and the $Q$-bands are at 520, 550, 594 and $652 \mathrm{~nm}$. The comparison of the spectral features shows that the absorption spectrum of dyad Z-10 in the visible region is also similar to a linear combination of the spectra of monomeric porphyrins 4 and Z-9.

Small differences exist between the bands maxima and intensities in the visible region of the absorption spectra of the dyad and those of its two monomeric components for both $E-\mathbf{1 0}$ and $Z-\mathbf{1 0}$. These might be accounted for by the fact that the monomeric macrocycles 4 and $\mathbf{9}$ used for comparison purposes are not identical to the structural units in the combined diporphyrin macrocycle, i.e. the electronic coupling between the moieties takes place in the ground state of the porphyrin dyads. However, the close similarity between the absorption spectrum of dyad $\mathbf{1 0}$ (both $E$ - and $Z$-) and the combined spectrum of porphyrins 4 and 9 (both $E$ - and $Z$-) is consistent with only weak interaction between the porphyrin moieties and the two chromophores retain their individual identities in the dyad arrays. This was also described for numerous dimeric porphyrins ${ }^{[32,43,44]}$ and results from the fact that the oscillator strengths for $Q(0,0)$ bands of the tetraphenylporphyrin molecules are not high enough in order to provide a strong interchromophoric coupling. On the other hand, the noticeable differences one may see in the Soret bands of the compounds under study (Figure 2). Firstly, the Soret band of every dyad is not a simple sum of Soret bands of equimolar mixture of the corresponding monomeric porphyrins. For dyad E-10 in which the spacer group has trans configuration, the absorption spectrum shows small red shift in the Soret band in comparison with a linear combination of the spectra of porphyrin monomers. The absorption spectra of both dyads show a distinct broadening in the Soret bands due to excitonic coupling of the strong $B$-transition dipoles of the two porphyrin constituents. Similar small spectral shifts with slight broadening of the Soret bands have been observed earlier in the absorption spectra of diporphyrins linked by phenylenevinylene ${ }^{[45]}$ and diphenylethyne bridges. ${ }^{[43,46]}$ Furthermore, the Soret bands of dyads $E-\mathbf{1 0}$ and $Z-\mathbf{1 0}$ differ from each other, which is due to the different excitonic interaction between the chromophores in these two dyads. The extent of excitonic coupling as known depends on the length and conjugative path of the spacer in the dimer and on the orientation of the porphyrin moieties. ${ }^{[21]}$ The only distinction between the diporphyrin systems discussed here consists in the different mutual orientation of the donor and acceptor chromophores resulting from the different configuration of the double bond in a spacer group, and that just may lead to the different excitonic coupling.

\section{Conclusions}

The porphyrin dyads $E-\mathbf{1 0}$ and $Z-\mathbf{1 0}$ consisting of 2-(2carboxyvinyl)-5,10,15,20-tetraphenylporphyrin and zinc 5-( $p$-aminophenyl)-10,15,20-triphenylporphyrin have been synthesized by coupling reaction between corresponding acid chloride derivatives and amino porphyrin. These dyads have two structural moieties separated by a relatively rigid amide linkage, which provides a weak electronic coupling between the chromophores. The porphyrin moieties of dyads differ in spectral characteristics in UV-vis region and hence in singlet state energies. Very recently, an efficient singletsinglet energy transfer from the $\mathrm{Zn}$ porphyrin to the free base porphyrin of these dyads after irradiation with visible light has been shown and reported. ${ }^{[36]}$ The energy transfer occurs with a rate constant of $\sim(2 \div 4.5) \cdot 10^{10} \mathrm{~s}^{-1}$ and almost quantitative efficiency. These results demonstrate that dyads $E-10$ and Z-10 may be suitable for solar energy conversion 
devices and have further potential application in the spectral sensitization of semiconductor solar cells.

\section{References}

1. Wasielewski M.R. Chem. Rev. 1992, 92, 435-461.

2. Gust D., Moore T.A., Moore A.L. Acc. Chem. Res. 2001, 34, 40-48.

3. Konovalova N.V., Evstigneeva R.P., Luzgina V.N. Russ. Chem. Rev. 2001, 70, 939-969.

4. Imahori H. Org. Biomol. Chem. 2004, 2, 1425-1433.

5. Fukuzumi S. Bull. Chem. Soc. Jpn. 2006, 79, 177-195.

6. Dunbar A.D.F., Brittle S., Richardson T.H., Hutchinson J., Hunter C.A. J. Phys. Chem., B 2010, 114, 11697-11702.

7. Maligaspe E., Sandanayaka A.S.D., Hasobe T., Ito O., D’Souza F. J. Am. Chem. Soc. 2010, 132, 8158-8164.

8. Wijesinghe C.A., Niemi M., Tkachenko N.V., Subbaiyan N.K., Zandler M.E., Lemmetyinen H., D’Souza F. J. Porphyrins Phthalocyanines 2011, 15, 391-400.

9. Harvey P.D., Filatov M.A., Guilard R. J. Porphyrins Phthalocyanines 2011, 15, 1150-1171.

10. Imahori H., Mori Y., Matano Y. J. Photochem. Photobiol., C 2003, 4, 51-83.

11. Hasobe T., Imahori H., Kamat P.V., Ahn T.K., Kim S.K., Kim D., Fujimoto A., Hirakawa T., Fukuzumi S. J. Am. Chem. Soc. 2005, 127, 1216-1228.

12. Jiang L., Li Y. J. Porphyrins Phthalocyanines 2007, 11, 299312 .

13. D'Souza F., Ito O. Chem. Commun. 2009, 4913-4928.

14. D'Souza F., Amin A.N., El-Khouly M.E., Subbaiyan N.K., Zandler M.E., Fukuzumi S. J. Am. Chem. Soc. 2012, 134, 654664.

15. Gust D., Moore T.A., Moore A.L. Acc. Chem. Res. 1993, 26, 198-205.

16. Maruyama K., Osuka A., Mataga N. Pure Appl. Chem. 1994, 66, 867-872.

17. Kurreck H., Huber M. Angew. Chem., Int. Ed. Engl. 1995, 34, 849-866.

18. Harriman A., Sauvage J.-P. Chem. Soc. Rev. 1996, 25, 41-48.

19. Imahori H., Sakata Y. Adv. Mater. 1997, 9, 537-546.

20. Imahori H., Sakata Y. Eur. J. Org. Chem. 1999, 2445-2457.

21. Lin V.S.-Y., Therien M.J. Chem. Eur. J. 1995, 1, 645-651.

22. Gust D., Moore T.A., Moore A.L., Krasnovsky A.A., Jr., Liddell P.A., Nicodem D., DeGraziano J.M., Kerrigan P., Makings L.R., Pessiki P.J. J. Am. Chem. Soc. 1993, 115, 56845691.

23. Springs S.L., Gosztola D., Wasielewski M.R., Král V., Andrievsky A., Sessler J.L. J. Am. Chem. Soc. 1999, 121, 2281-2289.

24. Wasielewski M.R., Johnson D.G., Niemczyk M.P., Gaines G.L. III, O’Neil M.P., Svec W.A. J. Am. Chem. Soc. 1990, 112, 6482-6488.
25. Shinoda S., Tsukube H., Nishimura Y., Yamazaki I., Osuka A. Tetrahedron 1997, 53, 13657-13666.

26. Osuka A., Marumo S., Mataga N., Taniguchi S., Okada T., Yamazaki I., Nishimura Y., Ohno T., Nozaki K. J. Am. Chem. Soc. 1996, 118, 155-168.

27. Kuz'mitskii V.A., Zen'kevich E.I., Gael V.I., Knyukshto V.N., Shul'ga A.M., Levinson E.G., Mironov A.F. J. Appl. Spectrosc. 1997, 64, 778-788.

28. Soares A.R., Martínez-Díaz M.V., Bruckner A., Pereira A.M., Tomé J.P., Alonso C.M., Faustino M.A., Neves M.G., Tomé A.C., Silva A.M., Cavaleiro J.A., Torres T., Guldi D.M. Org. Lett. 2007, 9, 1557-1560.

29. Tannert S., Ermilov E.A., Vogel J.O., Choi M.T., Ng D.K., Röder B. J. Phys. Chem., B 2007, 111, 8053-8062.

30. DeGraziano J.M., Liddell P.A., Leggett L., Moore A.L., Moore T.A., Gust D. J. Phys. Chem. 1994, 98, 1758-1761.

31. Milanesio M.E., Gervaldo M., Otero L.A., Sereno L., Silber J.J., Durantini E.N. J. Porphyrins Phthalocyanines 2003, 7, 42-51.

32. Kadish K.M., Guo N., Van Caemelbecke E., Froiio A., Paolesse R., Monti D., Tagliatesta P., Boschi T., Prodi L., Bolletta F., Zaccheroni N. Inorg. Chem. 1998, 37, 2358-2365.

33. Ravikumar M., Pandian R.P., Chandrashekar T.K. J. Porphyrins Phthalocyanines 1999, 3, 70-77.

34. Tomizaki K.Y., Lysenko A.B., Taniguchi M., Lindsey J.S. Tetrahedron 2004, 60, 2011-2023.

35. Malig J., Strauss V., Groenningen P., Guldi D.M., Jux N. J. Porphyrins Phthalocyanines 2011, 15, 1317-1325.

36. Paschenko V.Z., Konovalova N.V., Bagdashkin A.L., Gorokhov V.V., Tusov V.B., Yuzhakov V.I. Opt. Spectrosc. 2012, 112, 519-527.

37. Gribkova S.E., Luzgina V.N., Evstigneeva R.P. Zh. Org. Khim. 1993, 29, 758-762 (in Russ.).

38. Ponomarev G.V., Maravin G.B. Chem. Heterocycl. Compd. 1982, 18, 50-55.

39. Adler A.D., Longo F.R., Finarelli J.D., Goldmacher J., Assour J., Korsakoff L. J. Org. Chem. 1967, 32, 476-480.

40. Lindsey J.S. Synthesis of meso-Substituted Porphyrins. In: The Porphyrin Handbook, Vol. 1. (Kadish K.M., Smith K.M., Guilard R., Eds) San Diego: Academic Press, 2000. p. 45-118.

41. Locos O.B., Arnold D.P. Org. Biomol. Chem. 2006, 4, 902916.

42. Fungo F., Otero L.A., Sereno L., Silber J.J., Durantini E.N. J. Mater. Chem. 2000, 10, 645-650.

43. Wagner R.W., Lindsey J.S., Seth J., Palaniappan V., Bocian D.F. J. Am. Chem. Soc. 1996, 118, 3996-3997.

44. Hsiao J.-S., Krueger B.P., Wagner R.W., Johnson T.E., Delaney J.K., Mauzerall D.C., Fleming G.R., Lindsey J.S., Bocian D.F., Donohoe R.J. J. Am. Chem. Soc. 1996, 118, 11181-11193.

45. Burrell A.K., Officer D.L., Reid D.C.W., Scott S.M., Gordon K.C. J. Porphyrins Phthalocyanines 2000, 4, 626-633.

46. Loewe R.S., Lammi R.K., Diers J.R., Kirmaier C., Bocian D.F., Holten D., Lindsey J.S. J. Mater. Chem. 2002, 12, 1530-1552. 